\title{
Management of Retropharyngeal Node Metastases from Thyroid Carcinoma
}

\author{
Ashwini Reddy ${ }^{1}$ A. K. Verma $^{1} \cdot$ Sabaretnam Mayilvaganan $^{1}$
}

Published online: 31 July 2015

(C) Société Internationale de Chirurgie 2015

We read with interest the article titled, 'Management of retropharyngeal node metastases from thyroid carcinoma' by Hartl et al. [1]. We congratulate the authors on addressing the issue of Retropharyngeal lymph node metastasis in thyroid cancer in the era of PET scan, with the advent of which there has been an increase in the incidence of detection of recurrences and also there is an increasing dilemma for the knife happy Endocrine surgeon as to whether wait and watch or to intervene. We agree with the authors that these retropharyngeal nodes are difficult to visualize on routine ultrasonography, difficult to dissect, and difficult to decide on intervention. We also appreciate the art of combining original case series with review of literature which is apt for rare cases like Retropharyngeal Node Metastases in thyroid cancer. We have few queries which may be of interest for the future readers.

We would like to know the location of the tumor in relation to the thyroid lobe such as upper one-third, middle one-third, or lower one-third [2]. Did the authors record this finding? We would also like to know the side of the primary tumor and the retropharyngeal node in relation to the primary tumor such as ipsilateral or contralateral metastases. We would also like to know the average number of retropharyngeal nodes dissected by authors in each case [3] and also whether any non malignant node was found enlarged in the retropharyngeal space?

\section{References}

1. Hartl DM, Leboulleux S, Vélayoudom-Céphise FL, Mirghani H, Déandréis D, Schlumberger M (2015) Management of retropharyngeal node metastases from thyroid carcinoma. World J Surg 39(5):1274-1281. doi:10.1007/s00268-015-2947-2

2. Togashi T, Sugitani I, Toda K, Kawabata K, Takahashi S (2014) Surgical management of retropharyngeal nodes metastases from papillary thyroid carcinoma. World J Surg 38(11):2831-2837. doi:10.1007/s00268-014-2707-8

3. Shellenberger T, Fornage B, Ginsberg L, Clayman GL (2007) Transoral resection of thyroid cancer metastasis to lateral retropharyngeal nodes. Head Neck 29(3):258-266
Sabaretnam Mayilvaganan

drretnam@gmail.com

Endocrine Surgery, SGPGI, Lucknow, India 